\title{
Erratum to: Formal Description Techniques and Protocol Specification, Testing and Verification
}

\author{
Stan Budkowski ${ }^{1}$, Ana Cavalli ${ }^{1}$, and Elie Najm ${ }^{2}$ \\ 1 Institut national des télécommunications (INT), Evry, France \\ 2 Ecole Nationale Supérieure des Télécommunications (ENST), Paris, France
}

\section{Erratum to: \\ S. Budkowski et al. (Eds.) \\ Formal Description Techniques and Protocol Specification, Testing and Verification DOI: $10.1007 / 978-0-387-35394-4$}

The book was inadvertently published with an incorrect name of the copyright holder. The name of the copyright holder for this book is: (c) IFIP International Federation for Information Processing. The book has been updated with the changes.

The updated original online version for this book can be found at DOI: 10.1007/978-0-387-35394-4 